was now considerable and was accompanied by slight loss of blood. There were a dull aching pain and feeling of weight in the rectum and some slight difficulty in passing urine. On examination the rectum was not in itself found to be the cause of the trouble but a large tense swelling in Douglas's pouch was felt which was evidently causing the obstruction. Examination of the abdomen revealed a swelling in the right side of the hypogastrium. Above the pubes and to the left there were some hard, rounded lumps to be felt. Dr. R. A. Gibbons saw the patient the same day and elicited the information that because of prolapse of the uterus paraffin wax had been injected into the broad ligaments two years previously. The patient's temperature was normal and up to the time she consulted me she had been carrying out the details of her ordinary daily life.

On examination per vaginam (under an anæsthetic) the vagina was found to be considerably invaded by the swelling felt per rectum, the cervix was high up. and around it various hard round lumps could be felt. The uterus was not fixed. The tumour was obviously one of three things: an ovarian cyst, a parovarian cyst, or some collection of fluid in the broad ligament the result of the paraffin injection. Whichever it was, the necessity for operation was somewhat urgent.

On Nor. 9th I opened the abdomen, Dr. C. H. Roberts assisting me. I found a large tense swelling filling up the pelvis but there was no indication of a cyst in connexion with the uterine appendages and the swelling was adherent everywhere. In such circumstances it was not considered advisable to attempt anything further by the abdomen and the incision was closed by two continuous silk sutures for the peritoneum and fasciæ and interrupted fishing-gut sutures for the skin. With the patient in the lithotomy position the swelling was incised through the posterior wall of the vagina. Nearly 40 ounces of inodorous pus were evacuated mixed with a considerable amount of paraffin which came away in lumps and flakes. The incision was enlarged sufficiently to allow a digital examination of the abscess cavity. Various masses of paraffin could be felt but they were firmly fixed and the wall between them and the peritoneal cavity was so thin that no attempt was made to remove them. The cavity was washed out and a large-sized drainage-tube was introduced and sutured to the vaginal opening. The abscess cavity was irrigated twice daily with sterilised water, after which some peroxide of hydrogen was introduced. The cavity disappeared rapidly and at the end of 12 days a probe could only be passed one and a half inches through the incision in the vaginal wall and this small sinus soon healed. The abdominal incision healed well and the skin sutures were removed on the eighth day.

Everything went well until the twentieth day when there were a rise of temperature and some abdominal tenderness and swelling on the right side; this increased for the next three days. No definite swelling was felt per vaginam and I determined to reopen the abdominal wound, as it seemed possible that there was suppuration under the right rectus muscle. Under the anæsthetic the abdominal walls, which previously were rigid and extremely tender, became relaxed and moved freely. A small incision was made at the side of the former incision. The tissues were found to be quite healthy. The abdomen was opened and a large tense swelling was seen lying immediately under the right rectus. This was considered to be another separate collection of pus situated anteriorly and the abdominal incision was closed. Both Sir Francis Laking and Dr. Gibbons thought it highly desirable to wait until the swelling could definitely be felt in the vagina. This I decided to do.

The day after the second operation the temperature fell to normal and remained so. The abdominal swelling and tenderness rapidly diminished and at the end of a week, when the stitches were removed, the swelling had almost disappeared and there was hardly any tenderness. The patient left the nursing home to go to the seaside six weeks after the first operation, feeling and looking well, but there was still some tenderness under the right rectus on firm pressure.

CASE 2.-A woman, aged 66 years, was admitted into St. Mark's Hospital under my care on April 11th, 1904. She gave the following history. For three or four years previously she had suffered from prolapse of the rectum, the bowel protruding about three inches. Late in January, 1904, she was admitted into a hospital where she underwent operation, apparently by the injection of paraffin wax into both ischio-rectal fossæ; she was in hospital six weeks altogether.
A fortnight after leaving the hospital she "felt something burst behind" and noticed that her linen was covered with a white, waxy substance; since that time she had had a constant discharge from a small sinus in the right peri-anal region. The bowel had not prolapsed so much since the operation but she had suffered a good deal of pain in the back which was worse when sitting down.

On examination there was a hard, tender lump in the left buttock close to the anus; the skin over the lump was hot, dusky-red, and tender. On the right side, about half an inch from the anus, was the orifice of a sinus which ran up by the side of the rectum for about two and a half inches. A probe passed into the sinus could be felt beneath the mucous membrane but no definite internal opening could be made out. On squeezing the sinus small portions of wax and a little thin pus could be expelled. The patient was advised to return to the hospital at which she originally attended for further treatment, as this course on the whole seemed to be the most satisfactory. I have to thank my house surgeon, Mr. F. A. Johns, for the notes in this case.

Whether the injection of paraffin into the broad ligament is ever advisable or even justifiable is a question upon which I should like a definite opinion from those who make special study of the uterus and its appendages. The ultimate results in Case 1 were disastrous enough and there is no assurance that a recrudescence of the trouble may not occur at any time. Supposing that the paraffin is sterile at the time of injection, which is doubtful unless special precautions are taken, this is no guarantee that it will always remain so and, as these cases illustrate, it may possibly act as a culture medium in a part of the body where pyogenic micro-organisms always abound. The result in Case 2 is also unsatisfactory and having regard to the excellent results obtained by other methods in cases of prolapsus ani I do not think that the injection of paraffin wax is to be advocated.

The injection of paraffin wax has been used for cases of incontinence after excision of the rectum, but the result is not a success, there cannot be any control obtained by this injection. The paraffin wax forms a number of lumps round the lumen of the bowel, which is partially occluded, but the contents of the bowel escape as readily as before between the lumps. These remarks are not meant in any way to detract from the merits of this treatment in certain cases. The good results obtained are well known. The injection of paraffin wax, however, like many other new treatments, has been taken up and used without discrimination and unless this is checked a treatment which in proper cases produces excellent results may fall into disrepute.

Harley-street, W.

\section{ON THE RELATION BETWEEN VARIOUS ATMOSPHERIC CONDITIONS AND THE OCCURRENCE OF CEREBRAL HAMORRHAGE.}

By JaMeS W. RUSSELL, M.A., M.D. Cantab. M.R.C.P. LOND.

ASSISTAYT PHYSICIAN TO THE BIRMIXGHAM GENERAL HOSPITAL.

Dr. R. Hensleigh Walter has suggested 1 that in certain cases a high barometric pressure is a factor in deciding the onset of an attack of cerebral hæmorrhage, the especially favourable condition being, in his opinion, a sudden rise in the barometer following a more or less continued period of depression. Dr. Walter's letter was followed by others in support of his suggestion, in one of which the writer stated that he fully expects to be called to a case of cerebral hæmorrhage when the barometer has risen high and become anti-cyclonic. Other writers were in favour of a rise or fall in temperature as a probable exciting cause, especially when associated with changes in the atmospheric pressure, and it was evident that a belief in a causal relationship between atmospheric changes and the onset of apoplexy exists in the minds of many practitioners. The question can easily be put to the test and having recently collected for other purposes the cases of cerebral hæmorrhage admitted into the Birmingham General Hospital from the summer of 1885 to the end of 1902 I have the material 
ready to hand. My information as to the atmospheric conditions existing on the days of onset has been obtained from the records of the Edgbaston Observatory kept by $\mathrm{Mr}$. Alfred Cresswell, but as these have only been published since the beginning of 1891 only the cases occurring since that date have been available.

I have records of 66 fatal cases of cerebral hæmorrhage admitted into the General Hospital since January, 1891, in all of which the diagnosis was established by post-mortem examination. There are further 62 cases not terminating fatally (excluding those in which the exact date of onset was not determinable) which appear to me to have been probably due to hæmorrhage. In these, however, the diagnosis is somewhat open to question and it is possible that a certain number of cases of thrombosis may have been included and that others due to hæmorrhage may have been omitted. The inferences from these cases must therefore be regarded as to some slight extent doubtful and the two series have been throughout kept apart.

Barometric pressure. - The barometric readings from which my figures are obtained were taken at 9 A.M. They therefore only approximately represent the pressures obtaining at the actual moment of onset. But this source of error is hardly avoidable, especially as the notes often give no clue as to the time of day at which the attack began. The standard of comparison adopted is the average pressure for the 12 years involved. This, I have ascertained, amounts to 29.376 inches. The pressures recorded on the days of onset are as follows :-

$$
\begin{aligned}
& \text { Above the average Fatal. Non-fatal. Total. }
\end{aligned}
$$

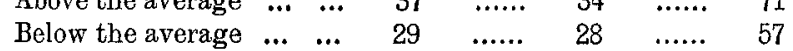

A larger number of cases therefore occurred on days on which the barometric pressure was above the average than on those when a pressure below the average was recorded, the proportion in the total number of cases being almost exactly as 5 to 4 . The relationship to the higher pressures of each month is shown in the next table :-

Fatal. Non- Total.

Occurring on the day of the maximum pressure of $\begin{array}{llllll}3 & \ldots & 3 & \ldots & 6\end{array}$

the month ... ...

Occurring on days with the pressure differing

from the maximum pressure of the month by $\} \begin{array}{lllll}8 & \ldots & 5 & \ldots & 13\end{array}$

not more than 0.1 inch

Occurring on the day after the maximum pressure

of the montli

$$
\begin{array}{lllll}
4 & \ldots & 3 & \ldots & 7
\end{array}
$$$$
\overline{15} \quad \overline{11} \quad \overline{26}
$$

These figures are probably to some extent matters of coincidence but they are considerably in excess of similar figures obtained with regard to the minumum pressure of the month, thus :-

$$
\text { Fatal. Non- Total. }
$$

Occurring on the day of the minimum pressure $\} \begin{array}{llllllll}1 & \ldots & 3 & \ldots & 4\end{array}$ of the month

Occurrirg on days with the pressure ${ }^{\prime}$ differing $\begin{array}{llllllllll}\text { from the minimum pressure of the month by } & 4 & \ldots & 2 & \ldots & 6\end{array}$

Occurring on the day after the minimum pressure

$\begin{array}{lllllllllll}\text { of the month } & \ldots & \ldots & \ldots & \ldots & \ldots & \ldots & \ldots & \ldots & & \end{array}$

$$
\begin{array}{lll}
\overline{8} & \overline{7} & \overline{15}
\end{array}
$$

Some little connexion between the onset of apoplexy and the higher pressures of the month seems thus to be suggested. But it is possible that variations in pressure may be of greater importance than the absolute height of the barometer. In order to work this out I have investigated the pressures recorded on the three consecutive days on the middle one of which the attack occurred. The explanation of the signs used is as follows:-

$<>=$ a day of higher occurring between two days of lower pressure.

$<=$ three successive days of rising pressure.

$>=$ three successive days of falling pressure.

$><=a$ day of lower occurring between two days of higher pressure.

The following are the results :-

$$
\begin{aligned}
& \begin{array}{llllllllllllll} 
& & & & & & & & & & & & >< \\
\text { Fatal } & \ldots & \ldots & \ldots & \ldots & 11 & \ldots \ldots & 23 & \ldots \ldots & 16 & \ldots \ldots . & 16
\end{array}
\end{aligned}
$$

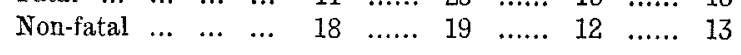

$$
\begin{aligned}
& \overline{29} \quad \overline{42} \quad \overline{28} \quad \overline{29}
\end{aligned}
$$

A considerable excess of cases therefore occurred in the course of a steadily rising barometer. In 19 of these the total rise exceeded $0.4 \mathrm{inch}$, in nine it exceeded $0.5 \mathrm{inch}$, but in only one was it more than one inch.

Taking the day of onset alone, 71 cases occurred with a rising barometer, compared with 57 noted when the barometer was falling. The proportion is again almost exactly as 5 to 4 and the evidence in favour of absolute height and of rise from a lower to a higher level as a factor in the causation of hæmorrhage is identical. The inference would probably be in favour of absolute height as the important factor.

Temperature.-It has been stated that cerebral hæmorrhage occurs more frequently in the colder months of the year. This was the case in the 241 cases admitted into the General Hospital since the summer of 1885,134 occurring from November to April inclusive, against 107 from May to October.

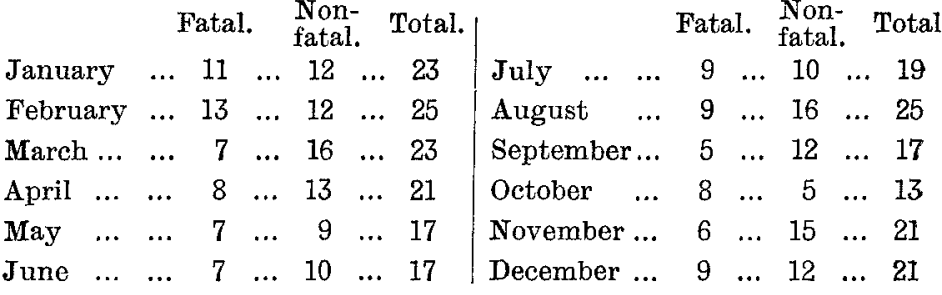

But the part, if any, played by temperature is more likely to be demonstrated by examining the daily fluctuations. This I have attempted to do by comparing the maximum and minimum temperatures recorded on the day of onset with the respective averages for the month.

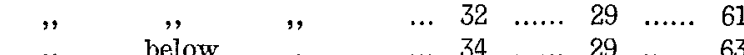

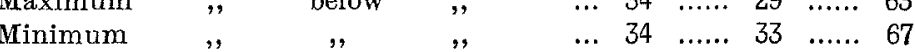

Temperature in itself is therefore not shown to have any effect in deciding the onset of an attack. Not much more can be said for the combined effects of barometric pressure and temperature, as shown below:-

\begin{tabular}{lllllllllll} 
& \multicolumn{1}{c}{} & \multicolumn{4}{c}{ Fatal. } & \multicolumn{4}{c}{ Non-fatal. } & Total. \\
B. + and T. + & $\ldots$ & $\ldots$ & $\ldots$ & $\ldots$ & 20 & $\ldots \ldots \ldots$ & 19 & $\ldots \ldots \ldots$ & 39 \\
B. + and T. - & $\ldots$ & $\ldots$ & $\ldots$ & $\ldots$ & 17 & $\ldots \ldots \ldots$ & 15 & $\ldots \ldots \ldots$ & 32 \\
B. - and T. + & $\ldots$ & $\ldots$ & $\ldots$ & $\ldots$ & 13 & $\ldots \ldots \ldots$ & 14 & $\ldots \ldots \ldots$ & 27 \\
B. - and T. - & $\ldots$ & $\ldots$ & $\ldots$ & $\ldots$ & 16 & $\ldots \ldots \ldots$ & 14 & $\ldots \ldots \ldots$ & 30
\end{tabular}

\begin{tabular}{|c|c|c|c|c|c|c|c|c|c|c|c|}
\hline Fatal & $\ldots$ & $\ldots$ & & & $<>$ & $\ldots \ldots$ & $\underset{19}{<}$ & ..... & $>$ & $\ldots$. & $\underset{24}{><}$ \\
\hline Non-fatal & $\ldots$ & $\ldots$ & $\ldots$ & $\ldots$ & 14 & $\ldots \ldots$ & 17 & ....... & 17 & $\ldots \ldots$ & 14 \\
\hline & & & & & - & & - & & - & & - \\
\hline & & & & & 25 & & 36 & & 29 & & 38 \\
\hline
\end{tabular}

There $\mathrm{B} .=$ barometric pressure, $\mathrm{T} .=$ maximum temperature, and the signs + and - represent excess over the average and the reverse.

Changes in temperature have been examined by taking the records on three consecutive days as before :-

The only possible suggestion that can be drawn from this table is that a rise of temperature on any particular day is slightly favourable to the occurrence of an attack, 74, or 57.8 per cent., of the cases occurring on days on which a rise of temperature was in progress. But this excess is only shown in the fatal cases.

The effect of combined changes in pressure and temperature on the actual day of onset is shown in the next table, in which the fatal and non-fatal cases are taken together:-

$\begin{array}{lllll}\text { Barometer rising and temperature rising } & \ldots & \ldots & 41 \text { cases. } \\ \text { Barometer falling and temperature falling } & \ldots & \ldots & 24 & , \\ \text { Barometer rising and temperature falling } & \ldots & \ldots & 30 & , \\ \text { Barometer falling and temperature rising } & \ldots & \ldots & 32 & \text {," }\end{array}$

In one case the same temperature was recorded on two successive mornings. The suggestion is that a combined rise of pressure and temperature is favourable to the occurrence of cerebral hæmorrhage; but in only 11 of the 41 cases of combined rise was the difference between the maximum temperature on the day of onset and that of the following day greater than $5^{\circ}$, and with only three exceptions this rise corresponded with a rise of barometric pressure of less than 0.2 inch. The evidence in favour of combined rise of pressure and temperature as a causal factor is thus extremely small and on the whole it seems fair to conclude that temperature, apart from season exerts little influence in the determination of an attack of apoplexy. 
Wind pressure.-The extreme pressure of the wind for each day is only recorded at the Edgbaston Observatory when it amounts to not less than 0.5 pound per square foot and in order to obtain the average pressure I have estimated it at 0.25 pound on those days on which no record is entered. The average extreme pressure for the 12 years is then $2 \cdot 2$ pounds. The cases are distributed as follows :-

\begin{tabular}{|c|c|c|c|c|}
\hline A h hre the averace & & Fatal. & & $\begin{array}{l}\text { Non-fatal. } \\
12\end{array}$ \\
\hline Below the arerage & 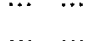 & 42 & $\cdots \cdots$ & 50 \\
\hline
\end{tabular}

Here the figures for the first time give a very definite result, the cases occurring on days of low wind pressure being $2 \cdot 6$ times as numerous as those which occurred when the wind pressure was above the average. This result must be taken for what it is worth. It is hard to believe that variations in wind pressure can play any part in the causation of apoplexy and a larger number of cases might, of course, dispose of the inference, but if statistics are worth anything in such matters the preponderance of cases on days of low wind pressure is almost too marked to be the result of coincidence only.

The final table sbows the distribution as regards wind pressure and barometric pressure combined :-

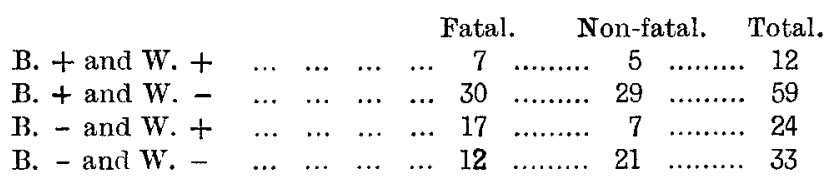

There is thus a very marked preponderance of cases on those days on which a high atmospheric pressure was combined with a low wind pressure.

Conclusions. - There seems to be a slight tendency towards the occurrence of cerebral hæmorrhage on days of high atmospheric pressure and also on days of rising pressure, the former being probably the important factor. There is a very marked tendency on days of low wind pressure and the combination of a low wind pressure with a high barometric pressure is the condition under which the largest number of cases took place. Apart from season, temperature in itself has not been shown to exert any influence, though a small excess of cases has been noted on days with a rising thermometer and also with a combined rise of atmospheric pressure and temperature.

Birmingham.

\section{THE OVARIAN LIGAMENT AND ITS RELATION TO PREGNANCY OCCUR- RING AFTER ABLATION OF THE OVARIES.}

BY JOHN H. DAUBER, M.B., B.CH. OXON., M.R.C.P. LOND.,

PHYSICIAN, WITH CARF OF OLT-PA'IEXTS, TO THE HOSPITAL TOR WOMEN, SOHO.

MoRPHOLOGY often throws light upon phenomena which are otherwise obscure and not easy of comprehension. Several cases have been placed on record where pregnancy has taken place notwithstanding the complete removal of both ovaries. Such cases naturally excite considerable interest. They are generally explained by the assumption that both ovaries have not in truth been entirely removed. Every operator knows how difficult, nay, impossible, it is in many instances of cystic and inflammatory conditions of the appendages to assert with absolute confidence that every trace of ovarian tissue has been taken away. Some of the cases recorded, however, seem indubitably to disprove this source of fallacy and it is generally believed either that accessory ovaries or additional patches of ovarian tissue like accessory thyroids in the neck may exist in the broad ligaments or that traces of ovarian tissue are present in the ligament of the ovary and are responsible for the ova which become fecundated under these unusual conditions. It is to be remembered that a single Graafian follicle is enough to accomplish the purpose. A consideration of the morphology of the orarian ligament makes the presence of Graafian follicles within it easily understandable and as the commonest facts are apt to be forgotten a reference to the subject may perhaps be excusable.

Hertwig, in his "Lehrbuch der Entwicklungsgeschichte," says of the inguinal ligament:-

The band is divided into three parts - the first from the lower end of the ovary to the uterus; the second part from the uterus to the inguinal region, the ligamentum teres; the third the uppermost, connecting the region, the ligamentum teres; the third the
parovarium with the hilum of the ovary.

McMurrich ("Development of the Human Body") speaks of its origin thus :-

From each genital ridge a prolongation of mesenchyme extends downward in the mesentery of the ridge, nearly parallel with the Millerian duct, with which it comes into contact at the part where the two ducts fuse and thence is continued downwards and forwaril between the folds of the broad ligament to be attached to the ventral wall of the abdomen in the inguinal region. The npper part of this prolongation of the genital ridge represents the ligament of the ovary and its lower part the ligamentum teres of the female, while in the male the entire structure forms what is known as the gubernaculum testis.

\section{Further-}

The change of position [of ovaries and testes] is partly due to the rate of growth of the inguinal ligaments being less than that of the abdominal walls, the reproductive organs being thereby drawn downward towards the inguinal regions where the ligaments are attached. The attachment is to the bottom of a slight pouch of peritoneum which projects a short distance into the substance of the genital swellings and is known as the canal of Nuck in the female and in the male as the raginal process. In the female a second factor combines with that just mentioned. The relative shortening of the inguinal ligament acting alone would draw the ovaries toward the inguinal region but the fusion of the lower ends of the Mullerian ducts, since the inguinal ligaments are united with these, produces a traction towards the median line so that the organs come to lie finally in the true pelvis.

Heisler ("Text-book of Embryology") says :The inguinal ligament in the female extends from the primitive
position of the ovaries in the lumbar region of the abdominal cavity to position of the ovaries in the lumbar region of the abdominal cavity to the groin where it passes through the abdominal wall, traversing the
inguinal canal, to terminate in the labium majus. The upper part of inguinal canal, to terminate in the labium majus. The upper part of the ligament containing involuntary muscular substance firmly unites with the ovary. In the third month the ovary descends to the lower
part of the abdominal cavity and is now connected by the succeeding part of the abdominal cavity and is now connected by the succeeding portion of the inguinal ligament with the uterus. This connexion may be a factor in the final position of the ovary-that is, its descent
into the true pelvis. The part of the inguinal ligament that passes into the true pelvis. The part of the inguinal ligament that passes from the ovary to the uterus is the permanent ligament of the ovary, while the remaining portion, which passes from the uterus through the inguinal canal to the labium majus of the vulva, is the round ligament of the uterus. As the inguinal ligament perforates the abdominal wall a small diverticulum of peritoneum goes with it. Normally, this peritoneal pouch subsequently becomes obliterated.

Arthur Keith ("Human Embryology and Morphology") describes these ligaments in the following terms :-

The round ligament of the uterus is attached to the Miillerian duct on each side. The point of attachment marks the junction of the uterine and Fallopian segments of the Millerian ducts. The round ligament corresponds to the gubernaculum testis in the male and its development is similar. .... Part of the Wolffian ridge is continued backwards as a peritoneal fold to the oroin, this part forming the inguinal fold. Into this peritoneal fold muscle cells grow from the rudiments of the transversalis and internal oblique in the abdominal wall and form the round ligament of the uterus. The point from which the ingrowth springs becomes the The point from which the ingrowth springs becomes the internal abdominal ring. Others grow out into the labium majus carrving with them a process of peritoneum, the canal of Nuck. The inguinal canal and external abdominal ring and extra-peritoneal part of the round ligament are thus formed. Also, the uppor part of the urogenital mesentery forms the diaphragmatic fold or plica vascularis. This in the female becomes the ovario-pelvic ligament. A fold of peritoneum, the inguinal fold or plica gubernatrix, continues the common uro-genital mesentery to the groin. The gubernaculum testis is developed in the plica gubernatrix; in the cor

emale the round ligament of the uterus appears. There is no trace of the inguinal canal in the third month; the various layers of the abdominal wall are unbroken. In the fourth month the deep muscular layer of the abdominal wall composed of the internal oblique and transversalis bencls inwards and expands the plica gubernatrix with muscular and fibrous tissue. The tissue (in the male) does not stop short at the uro-genital ridge and Miillerian duct as in the female but grows up and seizes the caudal pole of the testis.

Heisler states, with Bland-Sutton, Strangeways, and others, that involuntary muscular tissue extends to the ovary. Schäfer writes of it as follows :-

The reproductive gland is in both sexes at first attached directly to the Wolffian body which itself is attached by a fold of peritoneum to the back of the abdominal cavity, the mesorchium or mesovarium. $A$ band also passes from the Wolffian body upwards to the diaphragm and another containing involuntary muscular fibre-the plica gubernatrix-runs down towards the groin from the lower part of the Wolffian body and the duct.

From the foregoing extracts it will be seen that up to the present great uncertainty exists as to the exact mode of origin of the inguinal ligament and especially of the muscular tissue it contains. Is it laid down in situ? Does it grow downwards or upwards or both ? Are testicle and ovary dragged down by the muscular fibres of the inguinal ligament or are they to some extent at least retained in 